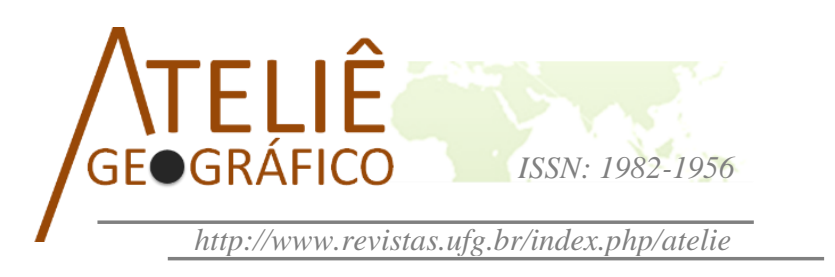

\title{
Classificação dos serviços ecossistêmicos prestados pelas áreas úmidas na zona estuarina do Rio Piancó-Piranhas-Açu (Nordeste, Brasil)
}

\author{
Classification of ecosystems services provided by wetlands \\ in the estuarine zone of the Piancó-Piranhas-Açu river \\ (Northeast, Brazil)
}

\section{Clasificación de los servicios ecosistémicos prestados por las zonas húmedas en la zona estuarina del Río Piancó- Piranhas-Açu (Nordeste, Brasil)}

\author{
Denise Santos Saldanha \\ Universidade Federal do Rio Grande do Norte \\ denisesaldanha.lama@gmail.com \\ Diógenes Félix da Silva Costa \\ Universidade Federal do Rio Grande do Norte \\ diogenesgeo@gmail.com
}

\begin{abstract}
Resumo
As áreas úmidas são ecossistemas importantes tanto para a sociedade como para a biodiversidade, apresentam-se em zonas de transição entre os ambientes terrestres e aquáticos, responsáveis por oferecer serviços para o bem estar humano e biológico, resultantes do seu capital natural. O presente trabalho teve como objetivo avaliar os serviços ecossistêmicos prestados pelas áreas úmidas no complexo estuarino do Rio Piancó-Piranhas-Açu (RN). Foi realizado o mapeamento e classificação das áreas úmidas, assim como a identificação dos serviços ecossistêmicos prestados na área de estudo. A partir desta perspectiva integrada da dinâmica entre o uso humano e seus reflexos nos processos ecológicos dos ecossistemas analisados (ex. manguezal, lagoas, lagunas, salinas solares, etc.), tem-se um melhor entendimento do desempenho destes processos, os quais propiciam a manutenção ou maior disponibilidade de serviços ecossistêmicos considerados chave para a gestão costeira.
\end{abstract}

Palavras-chaves: Capital Natural, Litoral Semiárido do Brasil, SIG, Classificação CICES.

\section{Abstract}

Wetlands are important ecosystems for both society and biodiversity, occur in terrestrial and/or aquatic areas and are responsible for providing services for human and biological 
well-being resulting from their natural capital. This study aimed to evaluate the ecosystem services provided by wetlands in the estuarine complex of the Piancó-PiranhasAçu River (State of Rio Grande do Norte). To this end, we performed the mapping and classification of wetlands, and identification of the ecosystem services provided in the study area. This integrated perspective of the dynamics between the human use and its reflexes in the ecological processes of the ecosystems analyzed (e.g. mangroves, lagoons, ponds, solar saltworks, etc.) enabled a better understanding of the performance of these processes, which promote the maintenance or greater availability of ecosystem services considered key to coastal management.

Key words: Natural Capital, Semi-arid coast of Brazil, GIS, CICES.

\begin{abstract}
Resumen
Las zonas húmedas son ecosistemas importantes tanto para la sociedad como para la biodiversidad, se presentan en zonas terrestres y/o acuáticas, y son responsables de ofrecer servicios para el bienestar humano y biológico, resultantes de su capital natural. El presente trabajo tuvo como objetivo evaluar los servicios ecosistémicos prestados por las áreas húmedas en el complejo estuarino del Río Piancó-Piranhas-Açu (RN). Se realizó el mapeo y la clasificación de las zonas húmedas, así como la identificación de los servicios ecosistémicos prestados en el área de estudio. A partir de esta perspectiva integrada de la dinámica entre el uso humano y sus reflejos en los procesos ecológicos de los ecosistemas analizados (ej. manglares, lagunas, salinas solares, etc.), se tiene un mejor entendimiento del desempeño de estos procesos, los cuales propician el mantenimiento o mayor disponibilidad de servicios ecosistémicos considerados clave para la gestión costera.

Palabras claves: Capital Natural, Litoral Semiárido de Brasil, SIG, Clasificación CICES.
\end{abstract}

\title{
Introdução
}

As Áreas Úmidas (AUs) são zonas de transição entre os ambientes terrestres e aquáticos, inundados periodicamente por água doce, salobra ou salina, sendo de origem natural ou artificial, continental ou costeira, apresenta uma biodiversidade/comunidades (fauna e flora) que se adaptam as condições do ambiente. Ocorre em quase todas as porções do globo, no Brasil, estes ecossistemas estão bem distribuídos, representando $20 \%$ do território, devido aos condicionantes físicos (clima, geologia, hidrografia, geomorfologia) locais (JUNK et al., 2014).

Estes ambientes são ecossistemas ricos em biodiversidade, devido à sua topografia aplainada, afetados diariamente pelos pulsos de maré. São de alta complexidade ecológica, responsáveis pelo equilíbrio e manutenção das espécies (SOARES; DOMINGUEZ, 2012). Dessa forma, este trabalho parte da problemática de que no Brasil, o atual cenário a ocupação da zona costeira se configura como um sério risco e comprometimento aos ecossistemas. No litoral semiárido do país, há uma rica diversidade de áreas úmidas costeiras e estuarinas, naturais e artificiais, onde as atividades humanas provenientes dos ecossistemas costeiros artificiais (carcinicultura e salinas solares) demandam bastante espaço para sua continuidade e expansão (COSTA et al., 2015). Burger (2000) e Costa (2017) destacam que em regiões áridas e semiáridas as principais áreas úmidas hipersalinas costeiras são: estuários, lagunas, lagoas, planícies hipersalinas, manguezal e apicuns, além de atividades econômicas como salinas solares e carcinicultura que são outros ecossistemas significantes na classificação de áreas úmidas artificiais. 
Por sua vez as salinas são vistas hoje como fonte de renda de diversos moradores que residem próximo ao seu entorno, além da produção econômica elas prestam diversos serviços ambientais (COSTA, 2013), servindo de habitat para diversas espécies, assumindo elevada importância ecológica no litoral semiárido em função da ausência de outros ecossistemas aquáticos que sustentam a biodiversidade costeira (lagunas e lagoas costeiras) (COSTA et al., 2014c). Esses ambientes são de alta produtividade, responsáveis pelo equilíbrio ecológico, servindo de abrigo/repouso, reprodução, desenvolvimento e alimentação de espécies, principalmente as espécies marinhas que vão a esses ambientes para desovar (ODUM, 1988; TUNDISI; TUNDISI, 2008).

Além das salinas e da carcinicultura, a região apresenta ecossistemas naturais (planícies hipersalinas e/ou apicuns e manguezal) que se destacam pelas suas fisionomias diferenciadas em função da semiaridez climática, fazendo com que estes ecossistemas ocupem espaços restritos próximos à desembocadura dos estuários (COSTA, 2010; COSTA et al., 2014a,b).

Segundo Junk et al. (2015), as áreas úmidas são ecossistemas importantes tanto para a sociedade como para a biodiversidade, apresentam-se em zonas de transição entre os ambientes terrestres e aquáticos, sendo responsáveis por oferecer serviços para o bem estar humano e biológico, resultantes do seu capital natural. Esses serviços são compreendidos como benefícios tangíveis (madeiras e alimentos) e intangíveis (regulação do clima e interações espirituais com o ecossistema), como por exemplo, a retenção de sedimentos, regulação do microclima, habitats para animais, manutenção da biodiversidade, além do ecoturismo e recreação para a comunidade local (COSTA, 2017).

No entanto, até o presente momento, não foi abordado de forma relevante uma caracterização ambiental da área de estudo, levando em consideração que ainda não existe uma classificação e quais os serviços ecossistêmicos prestados pelas áreas úmidas amplamente utilizadas no Brasil, havendo assim uma necessidade de classificar e identificar as áreas úmidas costeiras, sua extensão e distribuição (JUNK et al, 2014; COSTA, 2017).

Nesta perspectiva, esta pesquisa parte da hipótese de que na zona estuarino do rio Piancó-Piranhas-Açu ( $\mathrm{RN})$ encontra-se uma diversidade significativa de áreas úmidas, apesar da ocupação humana na zona costeira durante as últimas décadas em virtude do desenvolvimento de atividades econômicas (ambientes artificiais), no qual esses ecossistemas sofreram pressões e impactos de ações antrópicas, modificando as paisagens e o ambiente natural, havendo assim a necessidade de protegê-los e conservalos.

Esses ecossistemas até hoje prestam diversos serviços ecossistêmicos para a sociedade que moram no seu entorno. Considerando o exposto acima, o presente trabalho teve como objetivo avaliar os serviços ecossistêmicos prestados pelas áreas úmidas no complexo estuarino do Rio Piancó-Piranhas-Açu (RN). 


\section{Material e Métodos}

\section{Área de Estudo}

O sistema estuarino do rio Piancó-Piranhas-Açu está localizado nos municípios de Macau e Porto do Mangue (RN) (Figura 01), este é o maior e mais complexo do litoral setentrional do Rio Grande do Norte, sua foz em delta com presença de bancos arenosos tem vazão regularizada após a Barragem Armando Ribeiro Gonçalves de 17,8 m³/s (CBH-Piancó-Piranhas-Açu, 2017).

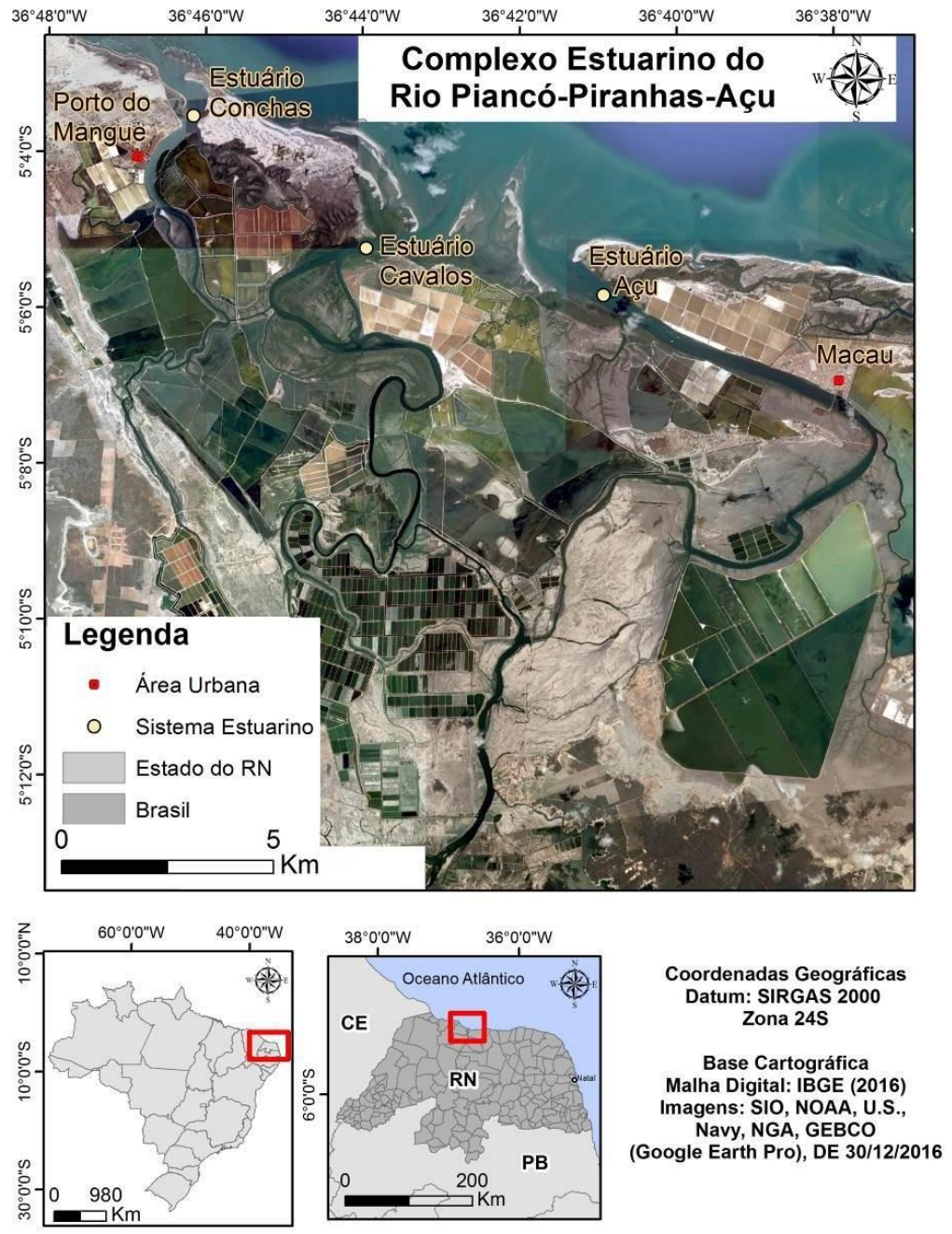

Figura 01: Sistema estuarino do Rio Piancó-Piranhas-Açu, litoral setentrional do estado do Rio Grande do Norte. 
Com a área de estudo de aproximadamente $20 \mathrm{~km}$ de largura, por cerca de 15 $\mathrm{km}$ de comprimento, este compõe um sistema de três canais estuarinos: Cavalos, Conchas e Açu, onde na paisagem é perceptível as diferentes produções do espaço, com a ação humana representada através de atividades econômicas voltadas a indústria petrolífera (óleo e gás), produção de sal (salinas solares), aquicultura (carnicultura), pesca, e turismo (ROCHA JUNIOR, 2011; ANA, 2014).

A área de estudo apresenta um clima semiárido, que segundo a classificação de Koppen, é uma região com características marcantes, quente e seco, com baixas precipitações, sofrendo anualmente estiagens (NIMER, 1979).

\section{Procedimentos Metodológicos}

Os procedimentos metodológicos utilizados na pesquisa para realizar a classificação das áreas úmida foram divididos em três etapas: 1) levantamento bibliográfico e cartográfico prévio da área; 2) montagem da base cartográfica, processamento de imagens digital e classificação das áreas úmidas encontradas na área de estudo; e 3) identificação preliminar dos serviços ecossistêmicos prestado na zona estuarina do rio Piancó-Piranhas-Açu (RN).

Inicialmente foi realizada a leitura e discussão de artigos científicos, com classificação A1 e B2, de acordo com o "qualis capes", além de livros e manuscritos publicados em periódicos nacionais e internacionais na área da pesquisa.

A segunda etapa foi subdividida em: 1) formação de um acervo de dados matriciais (raster); 2) armazenamento de dados vetoriais (vetor) no formato shapefile, que foram elaborados durante a identificação das áreas úmidas; e 3) dados quantitativos (planilhas, gráficos, tabelas) utilizados para auxiliar na distribuição das AUs identificadas.

A princípio, montou-se uma base de dados integrados em um Sistema de Informações Geográficas (SIG) com todos os sistemas de referências dos arquivos digitais em formato raster (imagens Landsat 8 e imagens do Google Earth Pro (Google $\odot$ ), além do armazenamento de dados vetoriais, que foram trabalhados em formato ".shp" (shapefile), tanto em relação aos arquivos elaborados referentes às áreas úmidas, como também os limites municipais e demais feições paisagísticas e políticoadministrativas foram adquiridas junto ao Instituto Brasileiro de Geografia e Estatística (IBGE), usando-se o elipsoide de referência o Datum SIRGAS 2000.

Em seguida, foram mapeadas as áreas úmidas presentes na área de estudo, utilizando-se imagens do satélite Landsat 8 (Data: 12/08/2016; Órbita/Ponto: 215/64 e Sensor OLI/TIRS), todas com resolução espacial de 30m e disponíveis de forma gratuita pelo Instituto Nacional de Pesquisas Espaciais (INPE).

Após o processo de mapeamento das áreas úmidas, foram quantificadas todas as zonas úmidas identificadas na área de estudo, nas quais foram feitas a tabulação e produção de tabelas e gráficos para representar melhor os dados da pesquisa. 
Por fim, foi realizada a classificação das áreas úmidas mapeadas na área de estudo, baseando-se na proposta Junk et al. (2014), através da nova classificação das áreas úmidas brasileiras, visando que essa classificação é o estudo mais completo sobre a temática abordada. Após isso, foram elaboradas planilhas, gráficos e tabelas.

Para classificar os serviços ecossistêmicos prestados no estuário PiancóPiranhas-Açu (RN) foi utilizado como base a classificação The Common International Classification of Ecosystem Services - CICES, em que os níveis hierárquico iniciam-se em uma descrição geral até uma mais específica. Os serviços avaliados foram enquadrados nas seguintes classes: 1) Serviços de provisão (provisão comida e outros recursos, etc.); 2) Serviços de regulação e manutenção (regulação da qualidade da água e do solo e degradação de áreas, etc.); e 3) Serviços culturais (benefícios recreacionais, de saúde física e mental, turismo, apreciação estética da paisagem e outros benefícios não materiais). Em cada uma dessas classificações gerais, há subdivisões e exemplos de quais são os serviços ecossistêmicos que ocorrem na zona estuarina do rio PiancóPiranhas-Açu/RN (HAINES-YOUNG; POTSCHIN, 2013).

\section{Resultados e Discussões}

Os resultados dessa pesquisa foram divididos em três etapas: a primeira constituiu na elaboração do mapa de localização das áreas úmidas presentes no complexo estuarino do rio Piancó-Piranhas-Açu (RN), a segunda foi a análise quantitativa da área total dos ecossistemas costeiros identificados e a terceira foi a identificação preliminar dos serviços ecossistêmicos prestados na área de estudo.

Segundo Costa (2013), as áreas úmidas presentes no semiárido, mais especificamente na área de estudo, estão diretamente relacionada aos fatores climáticos da região, devido a disponibilidade hídrica com o avanço periódico das marés, as altas temperaturas $\left(>28^{\circ} \mathrm{C}\right)$, baixa pluviosidade $\left(<800 \mathrm{~mm} \cdot\right.$ ano $\left.^{-1}\right)$ e a posição geográfica. A partir do mapeamento realizado juntamente com as visitas prévias de campo, foram identificados seis tipos de AUs (Figura 02): estuário, lagoas, salinas solares (artesanais e mecanizadas), carcinicultura, manguezal e apicum; sendo estes ecossistemas naturais e artificiais, considerados salinos e hipersalinos. 


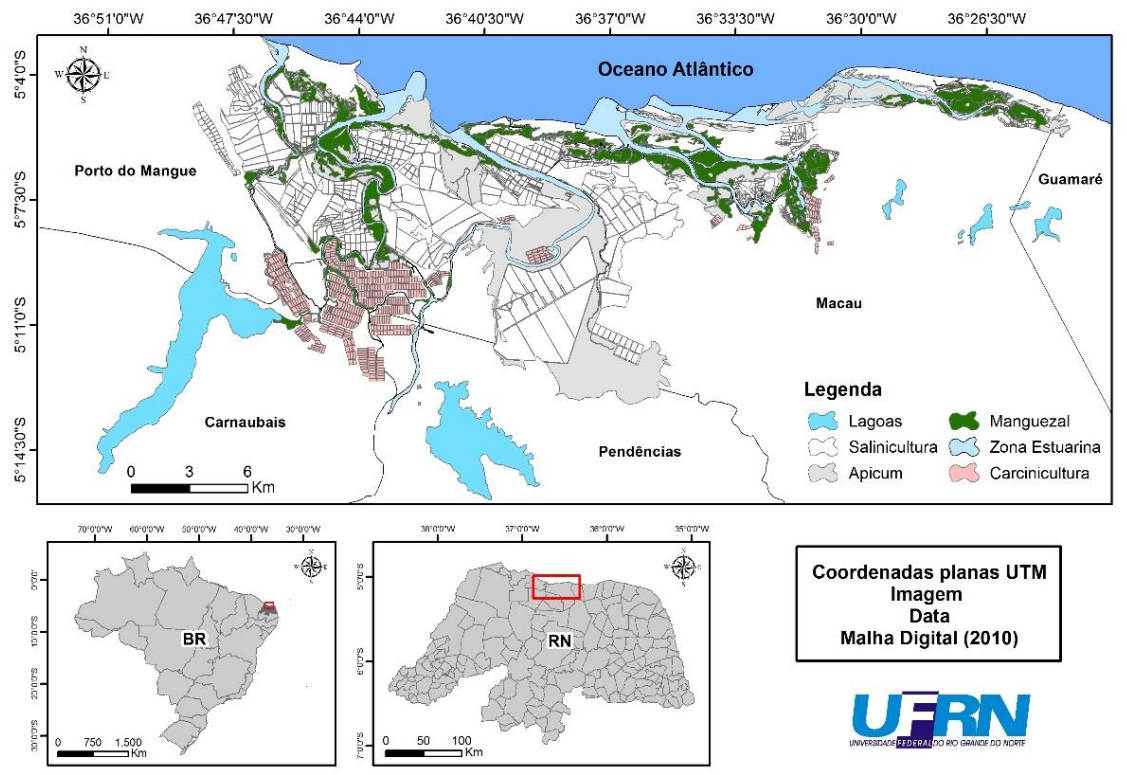

Figura 02: Identificação das AUs no sistema estuarino do rio Piancó-Piranhas-Açu (RN).

Com base no mapeamento, foi realizada a quantificação da área total ocupada pelas áreas úmidas hipersalinas da zona estuarina do rio Piancó-Piranhas-Açu. A área foi quantificada em quilômetros $\left(\mathrm{km}^{2}\right)$ e em hectares (ha) (Tabela 01), e pode-se constatar que os seis ecossistemas costeiros identificados na área de estudo ocupam uma área total de 29.900ha.

Tabela 01: Área total ocupada pelas áreas úmidas hipersalinas do complexo estuarino do rio Piancó-Piranhas-Açu (RN).

\begin{tabular}{|c|c|c|}
\hline Área Úmida & Área $\mathbf{( k m}^{\mathbf{2}}$ ) & Área (ha) \\
\hline Estuário & 32 & 3.200 \\
\hline Lagoas & 41 & 4.100 \\
\hline Salinas Solares & 107 & 10.700 \\
\hline Carcinicultura & 19 & 1.900 \\
\hline Manguezal & 39 & 3.900 \\
\hline Apicum & 61 & 6.100 \\
\hline Total & 299 & 29.900 \\
\hline
\end{tabular}

Fonte: Elaborado pelos autores. 
De acordo com a tabela 01, pode-se analisar a diversidade dos seis ecossistemas costeiros presentes na área de estudo, são distribuídos de forma heterogênea, sendo 36\% referente ao ecossistema artificial das salinas solares e a $6 \%$ referente a carcinicultura, sendo o menor ecossistema de ocupação na área. Ambas são classificadas como áreas úmidas artificiais antropogênicas.

A partir disso, os dados foram interpretados em esboço gráfico, representando a ocupação total da área de estudo por hectares (Figura 03). Pode-se analisar a variação dos ecossistemas de acordo com a localização deles na zona estuarina. Pode-se também perceber que na área de estudo o ecossistema predominante são as salinas solares (distribuídas entre salinas artesanais e mecanizadas), ocupando uma área de aproximadamente $36 \%$ de todo o território da bacia, com um total de $10.700 \mathrm{ha}$, os evaporadores e cristalizadores são responsáveis pela grande extensão das salinas solares.

De acordo com Costa et al. (2013), a partir da metade do século XIX, as salinas solares passaram por um processo histórico na região potiguar, sendo marcada pela construção dos primeiros tanques (evaporados e cristalizadores). Isso resultou no desenvolvimento industrial do polo salineiro, nos anos de 1930 e o fim de 1960 as salinas solares foram se modernizando, chegando a atingir um crescimento elevado na produção do mineral, e que nos dias de hoje atinge cerca de $95 \%$ de produção de todo país (ANDRADE, 1995).

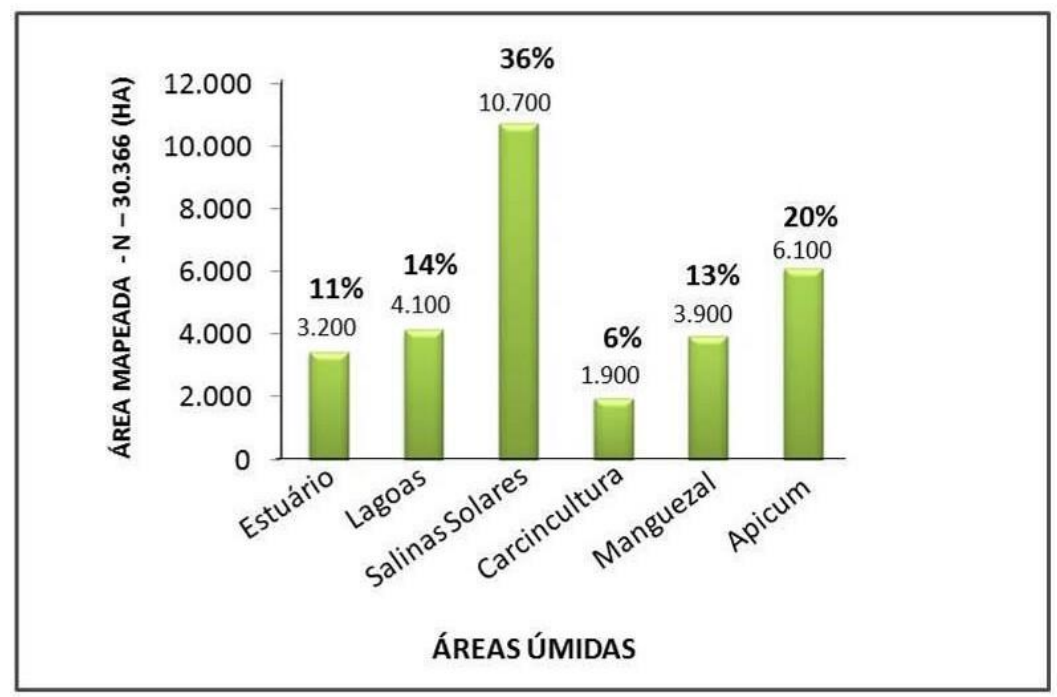

Figura 03: Histograma da área total mapeada em hectares das áreas úmidas hipersalinas da zona estuarina do rio Piancó-Piranhas-Açu (RN). 
Diante disso, houve o crescimento da ocupação das salinas solares, a produção do mineral cada vez mais avançada, fazendo a região ganhar visibilidade diante de outras áreas do país. A região era propícia a grandes demandas de produção devido aos fatores naturais da região semiárida, em termos climáticos essa zona apresenta: altas temperaturas $\left(>28^{\circ} \mathrm{C}\right)$, baixa precipitação pluviométrica $(<800 \mathrm{~mm} / \mathrm{ano})$, altas taxas de evaporação e disponibilidade hídrica (mar e/ou estuário), esses fatores são responsáveis pela alta ocupação dessa AU na área de estudo (COSTA, 2010; MOREIRA DA SILVA, 2016).

Em seguida vem o ecossistema apicum, que ocupa cerca de $20 \%$ do território da bacia, equivalente a $6.100 \mathrm{ha}$, correspondem a vastas áreas desnudadas ou cobertas com vegetação rasa, sendo o ecossistema natural com maior ocupação em toda área de estudo.

Os apicuns estão associados ao manguezal, tendo uma ocupação crescente sobre o ecossistema de manguezal, apresenta uma área considerável devido aos tanques de aquicultura e pelas áreas impactadas do manguezal, áreas degradadas. As ações antrópicas nessa região facilitam no desenvolvimento do ecossistema apicum, sendo áreas de pouca vegetação e que contém elevadas taxas de sal (UCHA; HADLICH; CELINO, 2008).

Os outros quatro ecossistemas (estuário, lagoas, manguezal e carcinicultura), são as áreas úmidas hipersalinas que apresentam dados semelhantes à ocupação da área de estudo. As lagoas apresentam 4.100ha (14\%) seguido do manguezal e estuário que ocupam, respectivamente, cerca de $3.900 \mathrm{ha}(13 \%)$ e $3.200 \mathrm{ha}(11 \%)$ da área total. A carcinicultura é uma atividade econômica desenvolvida na região, sendo o ecossistema com menor área da bacia, correspondendo a 1.900ha (6\%).

Logo em seguida, foi realizado a classificação dos ecossistemas hipersalinos de acordo com Junk et al. (2014), eles propõem que os sistemas sejam divididos em subsistemas, subclasses e macrohabitat (Quadro 01).

Os sistemas foram classificados em áreas úmidas costeiras e antropogênicas, dividindo as AUs costeiras em subsistemas sujeito aos impactos dos pulsos previsíveis de curta duração de maré e AUs separadas do mar com nível de água variável, apresentando subclasses de AUs marinhas, e em seguida tem os macrohabitat, que foram todos os ecossistemas hipersalinos identificados no mapeamneto. 
Quadro 01: Classificação das áreas úmidas hipersalinas do complexo estuarino do rio Piancó-

Piranhas-Açu (RN).

\begin{tabular}{|c|c|c|c|}
\hline SISTEMA & SUBSISTEMAS & SUBCLASSES & MACROHABITAT \\
\hline \multirow{4}{*}{ AUs costeiras } & \multirow{3}{*}{$\begin{array}{l}\text { AUs sujeitas aos } \\
\text { impactos dos } \\
\text { pulsos previsíveis } \\
\text { de curta duração } \\
\text { de maré }\end{array}$} & \multirow{4}{*}{ AUs marinhas } & Manguezal \\
\hline & & & Apicum \\
\hline & & & Estuário \\
\hline & $\begin{array}{c}\text { AUs separadas do } \\
\text { mar com nível de } \\
\text { água variável }\end{array}$ & & Lagoas \\
\hline \multirow{2}{*}{$\begin{array}{c}\text { AUs } \\
\text { antropogênicas }\end{array}$} & \multirow{2}{*}{ - } & & Salinas Solares \\
\hline & & & Carcinicultura \\
\hline
\end{tabular}

Fonte: Elaborado pelos autores, adaptado de Junk et al. (2015).

De acordo com a classificação de Junk et al. (2015), pode-se relatar os ecossistemas em áreas úmidas costeiras divididas em dois subsistemas: 1) áreas úmidas sujeitas aos impactos dos pulsos previsíveis de curta duração de maré, onde estão introduzidos os macrohabitats de manguezal, apicum, estuário e 2) áreas úmidas separadas do mar com nível de água variável, onde está introduzido apenas as lagoas costeiras.

No sistema de AUs antropogênicas são introduzidos apenas os macrohabitat, não há uma definição para os subsistemas e subclasses. Logo, os macrohabitat presentes na área de estudo são as salinas solares e a carcinicultura. São ecossistemas artificiais, que exerce atividades lucrativas na região, encontrados em áreas de planícies de maré, são ambientes que geram impactos positivos quanto negativos, sejam eles de natureza natural ou socioeconômica (JUNK et al., 2014).

Posteriormente a classificação das áreas úmidas, foram identificados os serviços ecossistêmicos prestados na área de estudo, através da classificação CICES pode-se dividir esses serviços em três classes: provisão, manutenção e/ou regulação e culturais (Quadro 02). As áreas úmidas hipersalinas proporcionam uma série de benefícios diretos ou indiretamente, sejam eles para beneficio do homem como também do próprio ambiente. 
Quadro 02: Classificação dos serviços ecossistêmicos prestados pelas áreas úmidas no estuário do Rio Piancó-Piranhas-Açu.

\begin{tabular}{|c|c|c|c|}
\hline CLASSES & DIVISÃO & GRUPOS & SERVIÇOS \\
\hline $\begin{array}{c}\text { Serviços de } \\
\text { Provisão }\end{array}$ & $\begin{array}{l}\text { Nutrição } \\
\text { Materiais } \\
\text { Energia }\end{array}$ & $\begin{array}{c}\text { Biomassa (ex. } \\
\text { plantas, origem } \\
\text { vegeta). } \\
\text { Filtrar } \\
\text { Fontes de energia } \\
\text { através da biomassa; } \\
\text { Energia mecânica. }\end{array}$ & $\begin{array}{c}\text { Alimentação } \\
\text { local/Gastronomia. } \\
\text { Compostos químicos } \\
\text { (óleos, base, cera); madeira } \\
\text { e frutos comestíveis. } \\
\text { Biocombustíveis } \\
\text { (biodiesel); } \\
\text { Eletricidade. }\end{array}$ \\
\hline $\begin{array}{c}\text { Serviços de } \\
\text { Manutenção e } \\
\text { Regulação }\end{array}$ & $\begin{array}{c}\text { Medição de } \\
\text { Resíduos. } \\
\text { Medição de fluxos. } \\
\text { Manutenção das } \\
\text { condições físicas, } \\
\text { químicas e } \\
\text { biológicas. }\end{array}$ & \begin{tabular}{|c|} 
Biorremediação \\
Fluxo de massa \\
\\
Fluxos líquidos; \\
manutenção do ciclo da \\
vida e habitat.
\end{tabular} & $\begin{array}{c}\text { Filtro biológico; } \\
\text { alimentação para as } \\
\text { populações de } \\
\text { halobactérias. } \\
\text { Estabilização de } \\
\text { sedimentos; controle de } \\
\text { erosão. } \\
\text { Manutenção do fluxo de } \\
\text { água; regulação climática. }\end{array}$ \\
\hline CLASSES & DIVISÃO & GRUPOS & SERVIÇOS \\
\hline $\begin{array}{l}\text { Serviços } \\
\text { Culturais }\end{array}$ & \begin{tabular}{|c|} 
Interações físicas e \\
intelectuais com \\
ecossistemas e \\
paisagens terrestre/ \\
marinhas. \\
\\
Divisão das interações \\
espirituais e simbólicas.
\end{tabular} & \begin{tabular}{|c|} 
Espiritual ou \\
Emblemático. \\
Interações físicas e \\
vivenciais. \\
\\
\\
Interações intelectuais e \\
representativas.
\end{tabular} & $\begin{array}{l}\text { Remédios naturais. } \\
\text { Valor paisagístico. } \\
\text { Valor cientifico; } \\
\text { educacional e } \\
\text { entretenimento. }\end{array}$ \\
\hline
\end{tabular}

Fonte: Adaptado de Haines-young e Potschin (2013). 
Os serviços de provisão de acordo com o quadro 02, estão subdivididos em: Nutrição, Materiais e Energia, dentro de cada divisão são apresentados grupos. Dentre a divisão "Nutrição", encontra-se o grupo da biomassa (ex. plantas, origem vegetal), que proporciona através do ecossistema do manguezal uma alimentação local a comunidade, neste ecossistema encontra-se crustáceos (caranguejos, camarões, siris e lagostas) e moluscos, são espécies responsáveis pela gastronomia da região. Ainda nessa divisão, encontra-se o ecossistema apicum que dispõem de plantas halófitas que são utilizadas como tempero na culinária local.

Na divisão "Materiais", o grupo tem a função de filtrar, no ecossistema de salinas solares, característicos dessa divisão, encontra-se a Artemia sp. que filtra naturalmente a salmoura, além das microalgas que exercem o papel de produzir compostos químicos (ex. óleos e base), propiciando produtos estéticos para a sociedade (DAVIS, 2000). Outro serviço é encontrado nessa divisão, a Carnaúba (Copernicia prunifera), localizada em áreas alagadas de planícies, proporciona a cera (retirada de suas folhas), como um produto utilizado no mundo todo. Além de sua madeira que é utilizada para o artesanato, responsável pela confecção de muitos produtos característicos da região. A matéria-prima das salinas e da carcinicultura é a água do mar ou dos estuários, ou seja, sustentável, compatibilizando com a divisão "matérias".

Já a divisão "Energia", é subdividida em dois grupos: fontes de energia através da biomassa e energia mecânica. Através das microalgas halofílicas, pode-se produzir biocombustíveis (como o biodiesel), devido elas produzirem glicerol e o $\beta$-caroteno. A produção do biocombustível tem um custo elevado, mas existem diversos estudos desde as décadas de 1980 e 1990 para que seja financeiramente viável, sendo aplicado em países como Israel e Estados Unidos. No processo de fonte de energia, utiliza-se apenas uma parte da biomassa como matéria-prima para a sua produção, gerando uma quantidade razoável de biomassa residual, que passa a ser aproveitada em decomposições para reciclar os nutrientes (OREN, 2002; AZEREDO, 2012; COSTA, 2013).

Ainda como fonte de energia mecânica, utiliza-se as variações das marés como potencialidades para gerar energia à base de recursos naturais, a partir das dinâmicas das correntes marítimas, ondas e gradientes de salinidade do mar. Diante disso, pode-se obter a eletricidade através da energia cinética, ou seja, do movimento das águas ou pela energia que deriva a partir da diferença do nível do mar entre as marés alta e baixa (ALVES, 2010).

Os serviços de "Manutenção e Regulação" divide-se em: medição de resíduos, medição de fluxo e manutenção das condições físicas, químicas e biológicas. Cada divisão apresenta um grupo diferente, na primeira divisão encontra-se a biorremediação, na segunda é o fluxo de massa e na terceira são os fluxos líquidos e a manutenção do ciclo da vida e habitat.

O grupo "Biorremediação" consiste em micro-organismos e microalgas realizarem a redução de contaminações no ambiente. Os ambientes com alta salinidade, 
especificamente as salinas, comportam um microcrustáceo (Artemia franciscana), que atua como uma espécie de filtro biológico das salmouras, ocasionando transformações nas substâncias químicas, afetando a interação trófica. Muitas vezes são dispersas no substrato bentônico, onde serve de proteico para as populações de halobactérias dos cristalizadores (COSTA, 2013).

Já o grupo "Fluxos de massa" ocorre o controle de taxas de erosão e a estabilidade de sedimentos, isso ocorre devido à presença de fragmentos de mangue, esses ambientes prestam serviços ambientais para o equilíbrio e manutenção da vida biótica. Ainda nesse grupo ocorre o transporte de sedimentos pelos rios, estuários até o mar.

A divisão "Manutenção das condições físicas, químicas e biológicas" é dividida em dois grupos: 1) fluxos líquidos, nesse grupo ocorre a manutenção do fluxo de água e a regulação climática, por exemplo, os estuários que são invertidos devido o clima semiárido do estado do Rio Grande do Norte conter altas taxas de evaporação e pouca precipitação, aumentando assim a salinidade dos estuários. O manguezal também atua no controle de enchentes, os fragmentos ocupam a linha de costa protegendo a população local em épocas de chuvas fortes e 2) manutenção do ciclo da vida e habitat, neste grupo o ecossistema manguezal serve de berçário e refúgios para diversas espécies, muitas delas se reproduzem e dispersam sementes e matéria orgânica, sendo um ecossistema que atua como equilíbrio biológico.

A classe dos serviços "Culturais" é dividida em: "Interações físicas e/ou intelectuais com ecossistemas e paisagens terrestre/ marinhas" e "Divisão das interações espirituais e simbólicas". Cada divisão apresenta um grupo, na primeira o grupo é espiritual ou emblemático, que corresponde da utilização das plantas como forma de serviços ecossistêmicos, ou seja, proporcionam através das plantas remédios naturais para a comunidade. O segundo grupo é subdivido em: 1) interações físicas e vivencias que utilizam das paisagens, dos animais e das plantas para o bem estar da sociedade e 2) interações intelectuais e representativas, que através do ambiente analisa os ecossistemas, sendo eles objetos de investigação, ou seja, áreas cientificas que resultam em trabalhos acadêmicos como teses, dissertações, trabalhos de conclusão de curso e artigos.

No quesito educacional, podem-se utilizar esses ambientes para praticas de educação ambiental, incentivando não só os professores locais a levarem seus alunos como também à comunidade em geral. Em relação à herança cultural podemos listar as salinas artesanais que são repassadas hereditariamente, muitos moradores locais tem apego ao lugar e continuam trabalhando nessas salinas, que até hoje seguem subsistindo como atividade econômica (SILVA, 2015).

No aspecto de entretenimento, auxiliam a saúde física e mental, através da admiração do ambiente, muitas pessoas se sentem bem em observar as paisagens de desertos salinos, dunas, salinas solares, vegetação, quanto a forma recreativa, admirando a diversidade estético-paisagística, e promovendo o ecoturismo. Além de 
utilizar estas paisagens como fonte de inspiração para a cultura local, na produção de quadros, pinturas, poemas, fotografias, entre outros.

\section{Considerações Finais}

Este estudo procurou mostrar que o complexo estuarino do rio Piancó-PiranhasAçu apresenta uma grande diversidade de áreas úmidas, partindo da hipótese de que a área de estudo apresenta uma diversidade de AUs apesar da ocupação humana.

Com isso, a metodologia empregada na identificação das AUs mostrou-se satisfatória, possibilitando classificar e identificar os ecossistemas costeiros. Com o uso das geotecnologias foi possível obter os resultados diante dos objetivos traçados, além da utilização da metodologia CICES que possibilitou o enquadramento dos serviços através da sua classificação.

A pesquisa teve como resultado a classificação e identificação das áreas úmidas hipersalinas no complexo estuarino do rio Piancó-Piranhas-Açu, além da identificação dos serviços ecossistêmicos prestados por esses ambientes. A partir da revisão bibliográfica e da utilização de ferramentas de geotecnologias, foram identificados e caracterizados os ecossistemas de manguezal, apicum, estuário, lagoas (ecossistemas naturais), além de atividades econômicas como salinas solares e carcinicultura (ecossistemas artificiais).

As AUs apresentaram um total de 30.366ha, sendo o ecossistema das salinas solares responsável pela maior ocupação na área de estudo, com $36 \%$ referente a 10.740ha da área total. A atividade salineira no Rio Grande do Norte ganhou muita visibilidade a partir de 1970 formando grandes unidades produtoras, grandes áreas de apicuns foram retiradas para a implantação de tanques (evaporadores e cristalizadores) como também para viveiros de camarões, que ainda é uma atividade econômica que ocupa pouco espaço, a carcinicultura é o ecossistema com menor área de ocupação da área de estudo, com apenas 6\% (1.965).

Os serviços ecossistêmicos foram classificados de acordo com CICES, divididos em: provisão, manutenção e regulação, e culturais. Os serviços ecossistêmicos de provisão são aqueles que são provenientes do capital natural que trás bens lucrativos para o homem, são eles: alimentação local/gastronomia, produtos de cosméticos, biocombustível (biodiesel), etc. Os serviços de manutenção e regulação são responsáveis por equilibrar a dinâmica do ambiente, atua como filtro biológico, controle de erosão, estabilidade dos sedimentos, manutenção do fluxo de água, regulação climática, etc.

Já os culturais são responsáveis pelo valor sentimental da sociedade, o apego ao lugar, às culturas e tradições. Atuam na crença da comunidade aos remédios caseiros, na educação e também no âmbito recreativo. É a maneira que a comunidade local consegue expressar seus conhecimentos que foram passados de maneira hereditária. 
Portanto, nesta pesquisa foi trabalhada a importância das áreas úmidas, tanto no âmbito ecológico, econômico como socioeconômico, realizando uma identificação preliminar dos serviços ecossistêmicos prestados por esses ambientes a comunidade local. A proposta torna-se de fundamental importância, porque há a necessidade de preservar e conservar essas áreas úmidas costeiras, assim espera-se, sobretudo, que esse trabalho venha a contribuir para o desenvolvimento de estudos mais aprofundados sobre a temática abordada.

\section{Agradecimentos}

Os autores agradecem a equipe do Laboratório de Biogeografia e ao Centro de Ensino Superior do Seridó (UFRN/CERES), pelo apoio logístico e instrumental, ao CNPq (MCTI/CNPQ/Universal 2014 Proc. 447227/2014-9) e a Pró-Reitoria de Pesquisa da UFRN (PVF10463-2014), pelo apoio financeiro desta pesquisa, assim como a CAPES, pela concessão de Bolsa de Pesquisa/Mestrado para DS Saldanha (CAPES/PPGE/UFRN).

\section{Referências}

ALBUQUERQUE, A. G. B. M.; FERREIRA, T. O.; NÒBREGA, G. N.; ROMERO, R. E.; SOUZA JÚNIOR, V. S.; MEIRELES, A. J. A.; OTERO, X. L. Soli genesis on hypersaline tidal flats (apicuns ecosystem) in a tropical semi-arid estuary (Ceará, Brazil). Soil Research, v. 52, p. 140-154, 2014.

ALVES, J. R. P. Manguezais: educar para proteger. Rio de Janeiro: FEMAR: SEMADS, 2001.

ALVES, L. R. Transformação da energia cinética de um fluxo de água em energia elétrica. Trabalho de conclusão de curso. Curso de Emgenharia de Computação, Centro Universitário de Brasília - UniCEUB, Brasília, 2010.

ANA - Agência Nacional de Águas (Brasil). Plano de recursos hídricos da Bacia Hidrográfica do rio Piranhas-Açu. Brasília: ANA, 2014. 312 p.

ANDRADE, D.C, ROMEIRO, A.R. Capital natural, serviços ecossistêmicos e sistema econômico: rumo a uma "Economia dos Ecossistemas". Texto para Discussão, São Paulo, IE/UNICAMP, n. 159, 2009.

ANDRADE, M. C. O território do sal: a exploração de sal marinho e a produção do espaço geográfico no Rio Grande do Norte. Natal: UFRN/CCHLA/Editora universitária, 1995. p. 73.

ARAÚJO, D. M. Caracterização do sistema produtivo de sal marinho nas salinas solares artesanais do estado do Rio Grande do Norte. 2013, 56 f. Monografia (graduação em geografia bacharelado) - Departamento de geografia, Universidade Federal do Rio Grande do Norte, 2013.

AZEREDO, V. B. S., Produção de Biodiesel a partir do cultivo de microalgas: estimativa de custos e perspectivas para o Brasil. Dissertação (Mestrado em Planejamento Energético). 2012. 171f. Universidade Federal do Rio de Janeiro/ Programa de Pós-Graduação em Planejamento Energético. Rio de Janeiro, 2012.

BAAS-BECKING, L. G. M. Historical notes on salt and salt-manufacture. Scient. Mon., N. Y., v. 32, p. 434-446, 1931. 
BONETTI-FILHO, J.; MIRANDA, L. B. Estimativa da descarga de água doce no sistema estuarino-lagunar de Cananéia-Iguape. Rev. Bras. Oceanografia, v. 45, n. 1/2, p. 89-94, 1997.

BRASIL. Decreto $n^{\circ} 1.905$, de 16 de maio de 1996. Promulga a Convenção sobre Zonas Úmidas de Importância Internacional, especialmente como Habitat de Aves Aquáticas, conhecidas como Convenção de Ramsar, de 02 de fevereiro de 1971. Disponível em:

<http://www.planalto.gov.br/ccivil_03/decreto/1996/D1905.htm> Acesso em: 03 de jan. 2018.

BURGER, M. I. Situações e ações prioritárias para conservação de banhados e áreas úmidas da Zona Costeira. Brasília: ANP, 2000.

CAVALCANTI. L.E. Aspectos Geoambientais da carcinicultura no Rio Grande do Norte e seus desdobramentos legais: a implementação da licença ambiental em defesa do meio ambiente.

Especial eletrônica, v. 10, p. 71-88, 2012.

CASCUDO, L. C. História do Rio Grande do Norte. 2 ed. Natal: Fundação José Augusto, 1984. $524 \mathrm{p}$.

CBH-PIANCÓ-PIRANHAS-AÇÚ. Comitê da bacia Hidrográfica do Rio Piancó- Piranhas-Açú. $A$ bacia. Disponível em:<http://www.cbhpiancopiranhasacu.org.br/site/a-bacia> Acesso em: 22 de setembro de 2017.

COLEMAN, M.J. Carbon Sequestration in Benthic Mats of Solar Ponds. In: Proceedings of the 9th International Symposium on Salt. Beijing: Gold Wall Press, 2009, p. 765-775.

COSTA, D.F.S. Análise fitoecológica do manguezal e ocupação das margens do estuário hipersalino Apodi/Mossoró (RN - Brasil). 2010. Dissertação (Mestrado) - Programa Regional de Pós-Graduação em Desenvolvimento e Meio Ambiente, Universidade Federal do Rio Grande do Norte, Natal, 2010.

COSTA, D. F. S.; DE MEDEIROS ROCHA, R.; CÂNDIDO, G. A. Perfil de sustentabilidade e uso dos recursos naturais em salinas solares no estuário do Rio Apodi-Mossoró (RN). In:

CÂNDIDO, G. A. (Org.). Desenvolvimento Sustentável e Sistemas de Indicadores de Sustentabilidade: formas de aplicações em contextos geográficos diversos e contingências específicas. Campina Grande - PB: Editora da Universidade Federal de Campina Grande, 2010, p. $401-426$.

COSTA, D. F. S. Caracterização ecológica e serviços ambientais prestados por salinas tropicais. 2013. 206f. Tese (Doutorado em Ecologia, Biodiversidade e Gestão de Ecossistemas) - Programa de Pós-graduação em Biologia, Departamento de Biologia, Universidade de Aveiro. Aveiro Portugal, 2013.

COSTA, D. F. S.; SILVA, A. A.; MEDEIROS, D. H. M.; LUCENA FILHO, M. A.; DE MEDEIROS ROCHA, R.; LILLEBO, A. I.; SOARES, A. M. V. M. Breve revisão sobre a evolução histórica da atividade salineira no estado do Rio Grande do Norte (Brasil). Sociedade \& Natureza, v. 25, n.1, p. 21-34, 2013.

COSTA, D. F. S; DE MEDEIROS ROCHA, R.; BARBOSA, J.E.L.; SOARES, A.M.V.M.; LILLEBO, A.I. Análise dos serviços ambientais prestados pelas salinas solares. Boletim Gaúcho de Geografia, v. 41, p. 206-220, 2014 a. 
COSTA, D. F. S.; DE MEDEIROS ROCHA, R.; CESTARO, L. A. Análise fitoecológica e zonação do manguezal em um estuário hipersalino. Mercator (Fortaleza), v. 13, p. 119-126, 2014b.

COSTA, D. F. S.; BARBOSA, J. E. L.; DE MEDEIROS ROCHA, R.; SOARES, A. M. V. M.; LILLEBO, A. I. Multifactorial analysis of the geochemical characterization in a Brazilian hypersaline floodplain Brazilian. Journal of Aquatic Science and Technology, v. 18, p. 89-90, 2014c.

COSTANZA, R. et al. The value of the word's ecosystem services and natural capital. Nature, v. 387, p. 253-260, 1997.

COSTANZA, R. et al. Changes in the global value of ecosystem services. Global Environmental Change, v. 26, p. 152-158, 2014.

DAVIS, J. Structure, function, and management of the biological system for seasonal solar saltworks. Glob. Nest J., v. 2, n. 3, p. 217-226. 2000.

ESTEVES, F. A. Fundamentos de Limnologia. Rio de Janeiro: Intersciência/FINEP, 2011.

GUEDES, D. R. C. Identificação dos padrões morfométricos dos ecossistemas aquáticos costeiros no litoral setentrional do Rio Grande do Norte. 2014. Monografia (Bacharelado em Geografia) Departamento de Geografia, Universidade Federal do Rio Grande do Norte, Caicó, 2014.

GUERRA, A. T; GUERRA, A. J. T. Novo dicionário geológico-geomorfológico. 6 ed. Rio de Janeiro: Bertrand Brasil, 2008, 652p.

HAINES-YOUNG, R.; POTSCHIN, M. Common International Classification of Ecosystem Services (CICES): Consultation on Version 4, August-December 2012 (2013). Disponível em <https://test.matth.eu/content/uploads/sites/8/2012/07/CICES20V43RevisedFinal_Report2901201 3.pdf>. Acesso em: 08/11/2017.

INSTITUTO BRASILEIRO DE GEOGRAFIA E ESTATÍSTICA - IBGE. Vocabulário Básico de Recursos Naturais e Meio Ambiente. 2d. Rio de Janeiro: IBGE, 2004. 32p.

JUNK, W. J.; PIEDADE, M. T. F.; LOURIVAL, R.; WITTMANN, F; KANDUS, P.; LACERDA, L. D.; BOZELLI, R. L.; ESTEVES, F. A.; NUNES DA CUNHA, C.; MALTCHIK, L.; SCHÖNGART, J.; SCHAEFFERNOVELLI, Y.; AGOSTINHO, A. A.; Brazilian wetlands: their definition, delineation, and classification for research, sustainable management, and protection. Aquatic Conservation: Mar. Freshw. Ecosyst., v. 24, p. 5-22, 2014.

JUNK, W. J.; PIEDADE, M. T. F.; LOURIVAL, R.; WITTMANN, F; KANDUS, P.; LACERDA, L. D.; BOZELLI, R. L.; ESTEVES, F. A.; NUNES DA CUNHA, C.; MALTCHIK, L.; SCHÖNGART, J.; SCHAEFFERNOVELLI, Y.; AGOSTINHO, A. A.; NÓBREGA, R. L. B.; CAMARGO, E. Definição e Classificação das Áreas Úmidas (AUs) Brasileiras: Base Científica para uma Nova Política de Proteção e Manejo Sustentável. In: NUNES DA CUNHA, C.; PIEDADE, M. T. F.; JUNK, W. J. (Org.) Classificação e Delineamento das Áreas Úmidas Brasileiras e de seus Macrohabitats. Cuiabá: EdUFMT, 2015, p. 13-82.

KOROVESSIS, N.; LEKKAS, T.D. Solar saltworks' wetland function. Global NEST Journal, v. 11, n. 1, p. 49-57, 2009. 
MAIA, L. P.; LACERDA, L. D. (orgs.). Estudo das áreas de manguezais do nordeste do Brasil: avaliação das áreas de manguezais dos Estados do Piauí, Ceará, Rio Grande do Norte, Paraíba e Pernambuco. Universidade Federal do Ceará. Instituto de Ciências do Mar. Fortaleza, 2005.

MOLION, L. C. B; BERNARDO, S. O. Uma revisão da dinâmica das chuvas no Nordeste brasileiro. Revista brasileira de Meteorologia, v. 17, n. 1, p. 1-10, 2002.

MOREIRA DA SILVA, D. E. Classificação das áreas úmidas costeiras da Zona Estuarina do Rio Apodi-Mossoró (RN). 2016. Monografia (Bachareladoem Geografia). Universidade Federal do Rio Grande do Norte. Centro de Ensino Superior do Seridó, Caicó, 2016.

MUNK, N. Inclusão dos Serviços Ecossistêmicos na Avaliação Ambiental Estratégica. 2015. 164f. Dissertação (Mestrado) - Universidade Federal do Rio de Janeiro/Programa de Pósgraduação em Planejamento Energético, Rio de Janeiro, 2015.

NAHLIK, A. M; KENTULA, M. E; FENNESSY, M. S; LANDERS, D. H. Where is the consensus? A proposed foundation for moving ecosystem service concepts into practice. Ecological Economics, v. 77, p. 27-35, 2012.

NIMER, E. Climatologia do Brasil. Rio de janeiro: IBGE, 1979. 421p.

ODUM, E. P. Ecologia. Rio de Janeiro: Guanabara, 1988.

OREN, A. Biotechnological applications and potentials of halophilic microorganism. In: OREN, A. Halophilic microorganisms and their environments cellular origin - Life in extreme habitats and astrobiology, v. 5, n. 3., p. 357-388, 2002.

OREN, A. Saltern evaporation ponds as model systems for the study of primary production processes under hypersaline conditions. Aquat. Microb. Ecol., v. 56, p. 193- 204, 2009.

ORTIZ-MILAN, S.M.; DAVIS, J.S. Behavior of the detrimental microorganisms for the solar salt production in the presence of a helpful population of brine shrimp in the ISYSA solar saltworks. In: Proceedings of the 2nd International Conference on the Ecological Importance of Solar Saltworks. Merida, 2009.

PIEDADE, M. T. F.; JUNK, W. J.; SOUZA JR, P. T.; NUNES DA CUNHA, C.; SCHÖNGART, J.; WITTMANN, F.; CANDOTTI, E.; GIRARD, P. As áreas úmidas no âmbito do Código Florestal brasileiro. In: Comitê Brasil em Defesa das Florestas e do Desenvolvimento Sustentável. Brasília: Comitê Brasil, 2012. p. 9-17.

PRITCHARD, D. W. What is an estuary: physical view point? In: LAUFF G. H. (Ed). Estuaries. Washington, D. C.: American Association for the Advance of Science, 1963.

PROST, M. T. (coord.). Projeto Manguezais paraenses: recursos naturais, usos sociais e indicadores para a sustentabilidade. Relatório Final. Belém: MCT/Museu Paranaense Emilio Goeldi, SECTAM, 2001. CD-ROM. (Programa de Estudos Costeiros, PEC).

RABELO, M. S. A cegueira do óbvio: A importância dos serviços ecossistêmicos na mensuração do bem-estar. 2014. 136f. Tese (Doutorado em Desenvolvimento e Meio Ambiente). Universidade Federal do Ceará, Fortaleza, 2014.

RAHAMAN, A.A.; AMBIKADEVI, M.; SOSAMMA-ESSO. Biological management of Indian solar saltworks. 7th Symp on Salt, v. 1, p. 633-643, 2009. 
RAMSAR. The Ramsar Convention Manual: a Guide to the Convention on Wetlands (Ramsar, Iran, 1971), 4 ed. Gland, Switzerland: Ramsar Convention Secretariat, 2006. RIBEIRO, L. F.; SOUZA, M. M.; BARROS, F.; HATJE, V. Desafios da carcinicultura: aspectos legais, impactos ambientais e alternativas mitigadoras. Revista de Gestão Costeira Integrada/Journal of Integrated Coastal Zone Management, v. 14, n. 3, p. 365- 383, 2014.

ROCHA JUNIOR, J. M. Avaliação ecológica-econômica do manguezal de Macau/RN e a importância da aplicação de práticas preservacionistas pela indústria petrolífera local. 2011. 100 f. Dissertação (Mestrado) - Programa de Pós- graduação em Ciências e Engenharia do Petróleo, Departamento de Ciências Exatas e da Terra. Natal, 2011.

ROCHA, E. A. Diversidade funcional em comunidades de peixes lagunares no sul do Brasil. Dissertação (Mestrado em Ecologia). Universidade Federal do Rio Grande do Sul, 2014.

RUTE DA SILVA, A; COSTA, D. F. S. Matriz Swot aplicadas nas salinas solares artesanais do Litoral Setentrional do Rio Grande do Norte. $1^{\circ}$ Encontro Nacional de Planejamento UrbanoRegional no Semiárido. Pau dos Ferros, 2016.

SANTOS, M.C. Contribuição à gestão das lagoas costeiras: conhecimento tradicional, técnico e científico associado ao manejo dos recursos naturais da Lagoa de Carapebus, parque nacional restinga de Jurubatiba - RJ, 2008, 135 f. Dissertação (Pós-Graduaçao em Engenharia Ambiental) - Centro Federal de Educação Tecnológico de Campos, CEFET, 2008.

SANTOS, P. P. Evolução econômica do Rio Grande do Norte (Século XVI a XXI). 3 ed, Natal: Departamento Estadual de Imprensa, 2010.

SCHAEFFER-NOVELLI, Y.; CINTRÔN-MOLERO, G.; ADAIME, R. R.; CAMARGO, T. M. Variability of mangrove ecosystems along the Brazilian coast. Estuaries, v. 13, n. 02, p. 204-218, 1990.

SCHAEFFER-NOVELLI, Y. Grupo de ecossistemas: manguezal, marisma e apicum - principais vetores de pressão e as perspectivas para sua conservação e usos sustentáveis. Brasília/DF: Instituto Brasileiro de Meio Ambiente e Recursos Naturais Renováveis - IBAMA, 2005.

SCHETTINI, C. A. F. Caracterização Física do Estuário do Rio Itajaí-açu, SC. Revista Brasileira de Recursos Hídricos, v.7, n.1, p. 123-142, 2002.

SILVA, M. C. Estuários - critérios para uma classificação ambiental. Revista Brasileira de Recursos Hídricos, v.5, n.1, p. 25-35, 2000.

SILVA, A. R. Produção artesanal de sal marinho no litoral setentrional do Rio Grande do Norte. 2015. Monografia (Bacharelado em Geografia). Universidade Federal do Rio Grande do Norte. Centro de Ensino Superior do Seridó, Caicó, 2015.

SOARES, G. S.; DOMINGUEZ, J. M. L. Zonas úmidas na planície costeira do rio Itapicuru, litoral norte do estado da Bahia, Brasil: classificação e controles ambientais. Revista da Gestão Costeira Integrada, v, 12, n. 2, p. 223-237, 2012.

TAHIM, E. F.; ARAÚJO JUNIOR, I. F. A carcinicultura do nordeste brasileiro e sua inserção em cadeias globais de produção: foco nos APLs do Ceará. Rev. Econ. Sociol. Rural, v. 52, n. 3, 2014.

TRINDADE, S. L. B. História do Rio Grande do Norte. Natal: Editora do IFRN, 2010. 
TUNDISI, J. G.; MATSUMURA-TUNDISI, T. Limnologia. São Paulo: Oficina de textos, 2008.

UCHA, J. M; HADLICH, G. M.; CELINO, J. J. Apicum: Transição entre solos de encosta e de manguezais. Revista E. T. C., v. 5, p. 58-63, 2008.

VALLE-LEVINSON, A. Definition and classification of estuaries. In: (Org.). Contemporary issues in estuarine physics. Cambridge University Press, 2010, p. 1-11.

WHETSTONE, J. M.; TREECE, G. D.; BROWDY, C. L.; STOKES, A. D. Opportunities and Constraints in Marine Shrimp Farming. SRAC, n. 26, p. 1-8, 2002. ZEDLER, J. B. Wetlands at your service: reducing impacts of agriculture at the watershed scale. Frontiers in the Ecology and the Environment, v. 1, n. 2, p. 65- 72, 2003.

\footnotetext{
Denise Santos Saldanha

Mestranda em Geografia pela Universidade Federal do Rio Grande do Norte UFRN (Campus Natal). Graduação em Geografia pela Universidade Federal do Rio Grande do Norte - UFRN (Campus Caicó/2018). Atua no laboratório de Biogeografia (LABIGEO). Membro do TRÓPIKOS - Grupo de Pesquisa em Geoecologia e Biogeografia Tropical.

Endereço: Centro de Ensino Superior do Seridó, sn. Penedo. Caicó-RN, CEP 59.300-000.

E-mail: denisesaldanha.lama@gmail.com

Diógenes Félix da Silva Costa

Geógrafo e Doutor em Ecologia. Professor Adjunto III do Depto. de Geografia da UFRN. Docente permanente dos cursos de Mestrado Acadêmico em Geografia e Mestrado Profissional em Ensino de Geografia da UFRN e docente colaborador do Mestrado e Doutorado em Ecologia e Conservação da UEPB. Coordena o LABIGEO - Laboratório de Biogeografia da UFRN e lidera o TRÓPIKOS - Grupo de Pesquisa em Geoecologia e Biogeografia de Ambientes Tropicais. É membro integrante do Instituto Nacional de Áreas Úmidas - INAU II (Rede Nacional de INCTs/CNPq), coordenando o sub-projeto "Delineamento e caracterização das áreas úmidas hipersalinas do litoral semiárido do Brasil" (convênio MCTI/CNPq/CAPES/FAPs - Proc.465436/2014-5/2017-2020). Atualmente, é Bolsista de Pós-Doutorado Júnior/CNPq no Programa de PósGraduação em Geografia da UFPB (Mestrado/Doutorado).

Endereço: Centro de Ensino Superior do Seridó, sn. Penedo. Caicó-RN, CEP 59.300-000.

E-mail: diogenesgeo@gmail.com
} 